\title{
Centralized Scheduling of Distributed Energy Resources in an Isolated Micro grid
}

\author{
R. Vanitha
}

\begin{abstract}
Micro grid comprises of various Distributed Energy Resources, Battery Energy Storage System (BESS) and various loads that can be connected to a grid or can be operated in an isolated mode. In this paper, micro grid comprises of a Diesel Generator set, wind turbine generator, Battery Energy Storage System (BESS) to feed a critical load in an isolated location. The intermittent energy from wind power is stored in BESS and a Centralized micro controller program is used to schedule the operation of Diesel Generator and BESS to provide an uninterrupted power supply to the critical load. The communication link between the microcontroller and Distribution Energy Resources will be a satellite link (GPRS/3G/4G/5G) or optical fibre cable. The main objective of this work is to reduce the usage of diesel generator output and utilizing the renewable energy in place of it to its maximum capacity. Meanwhile by proper scheduling, continuous working of BESS is ensured within its SOC limits. In this work, MATLAB simulation is used to simulate the load sharing among Diesel Generator and BESS. $A$ hardware prototype is designed in proteus software and the hardware prototype is fabricated to verify the simulation results.
\end{abstract}

Keyword-Distributed Energy Resources, Diesel Generator, Wind turbine generator, centralized scheduling, Isolated Micro grid, Battery Energy Storage systems

\section{INTRODUCTION}

In islands and remote areas where there is no main grid connection due to economical and geographical reasons, Diesel generators are only sources to meet the loads.

There are many disadvantages associated with Diesel generator like increase in oil prices, limited availability and carbon emissions that affect the green environment. With the emerging development of renewable sources, usage of Diesel generators can be minimized for Energy production. This paper mainly focuses on proper scheduling of diesel generators and battery energy system to minimize usage of diesel sets.

The usage of diesel generators for power generation in places like island is minimized by use of distributed energy resources and battery energy management system [1]. The battery cost is minimized in a hybrid system and a optimal scheduling is achieved between renewable sources and battery system [2]. Coordinated control is used to have a smooth scheduling between renewable energy sources and battery in islanded Ac micro grid [3]. A new control strategy by controlling the SOC limit of the battery is proposed to control the generated powers of renewable energy sources in an autonomous micro grid [4]. A Battery Energy Storage dispatch control algorithm is developed to provide reliability in supply by the intermittent wind farms [5].

Control strategies are modelled to minimize hybrid renewable resources with battery system cost as well to have optimal power scheduling among them [6]

Revised Version Manuscript Received on 16 September, 2019.

* Correspondence Author

R. Vanitha, Professor, Department of Electrical and Electronics Engineering, Sathyabama Institute of Science and Technology, Chennai, Tamilnadu, India vanithasi@yahoo.com .
The frequency and voltages in standalone micro grid with high penetration of intermittent renewable sources is controlled using reactive power and real power droop control [7]. A power dispatch control in Energy management system is proposed to minimize the usage of diesel powers in micro grid. [8]. Stability and power control in an islanded micro grid is achieved using frequency control approach without any centralized controller [9]. The same frequency control is used with master slave approach in detecting power shortages and balancing it by sharing real power [10].document is a template.

The main objective of this paper is to have centralized controller for scheduling between Diesel generator and Battery storage system to provide an uninterrupted supply to a critical load. This paper is organized in a way briefing the introduction, literature survey and objective in this current section. Section II explains the proposed Centralized Controlling system for Standalone Power grid continued by the simulation of the proposed system in section III. The Hardware prototype with its simulation in proteus 7 design suit and its results are discussed in section IV and conclusion of the paper is dealt in section $\mathrm{V}$.

\section{Proposed Centralized Controlling System for STANDALONE POWER GRID}

The proposed system shown in Fig. 1 comprises of a Diesel Generator set and a wind turbine generator with a battery energy storage system as a sources and a critical load. The sources and load are at a remote place. A centralized controller will receive information about oil level, diesel level from Diesel generator set, wind speed levels from wind turbine and the state of charge (SOC) limits of Battery storage systems through satellite communication or through a optical fibre cable. Since wind power is intermittent, whenever there is a generation of power it will be stored in battery storage system using AC to DC converter and a charge controller. Generally Diesel Generator supplies the critical load. When the battery reaches the specified SOC limit, the centralized controller will start the operation of battery and stop the Diesel generator operation till the battery level attains the DOD limits, then automatically operation is transferred to Diesel generator. This process helps in minimizing the Diesel usage and effective utilization of Renewable power through battery. 


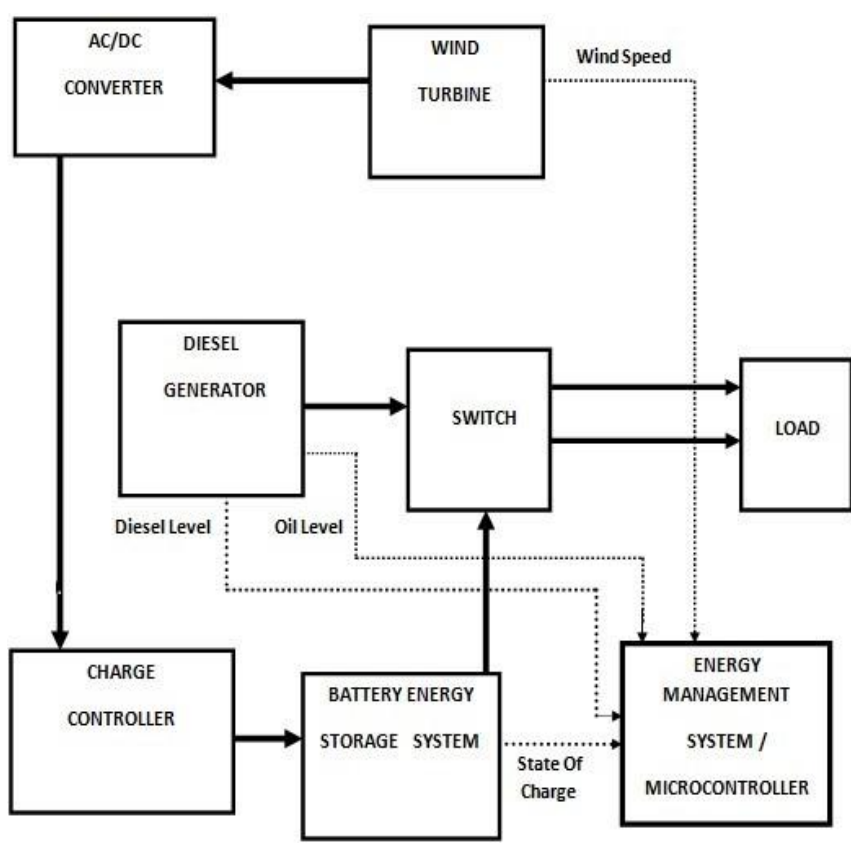

Fig. 1. Block diagram of Proposed Centralized Controlling system for Standalone Power grid

\section{SIMULATION AND DISCUSSION OF RESULTS OF PROPOSED SYSTEM}

The Critical load has to be supplied with constant power without any interruption. The required constant power levels from Diesel generator and Battery energy system is checked using the Simulation with Simulink in MATLAB version R2018a. Fig. 2 represents the simulation diagram for generating $4 \mathrm{Kw}$ power using diesel generator and Fig. 3 depicts the simulation diagram for generator the same level of power using battery storage system. Proper parameters of diesel generator and battery storage system are chosen in simulation to produce same level of power.

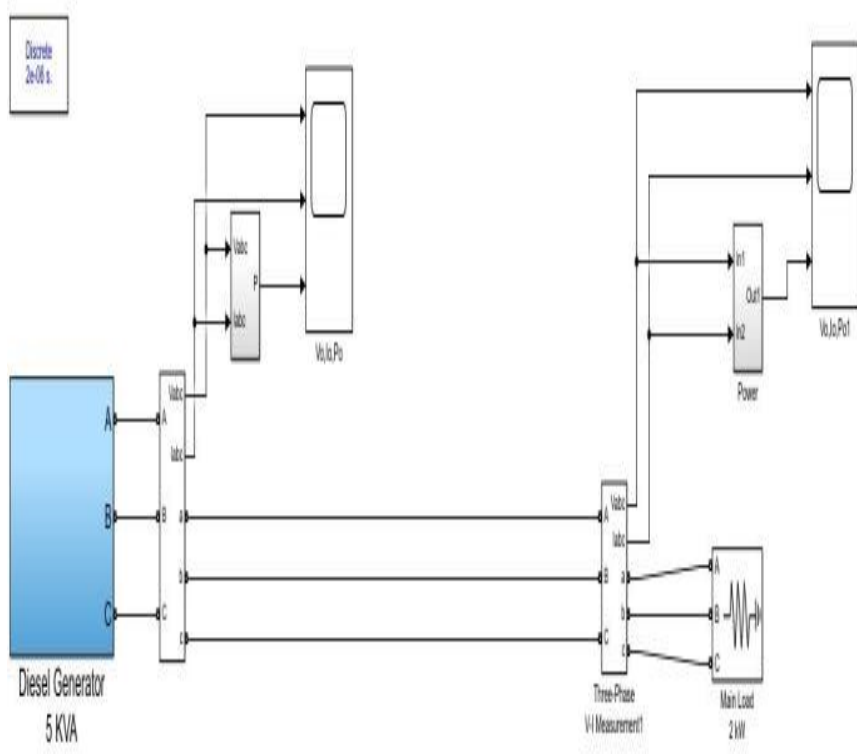

Fig. 2. Simulation Diagram of Diesel Generator supplying the critical load

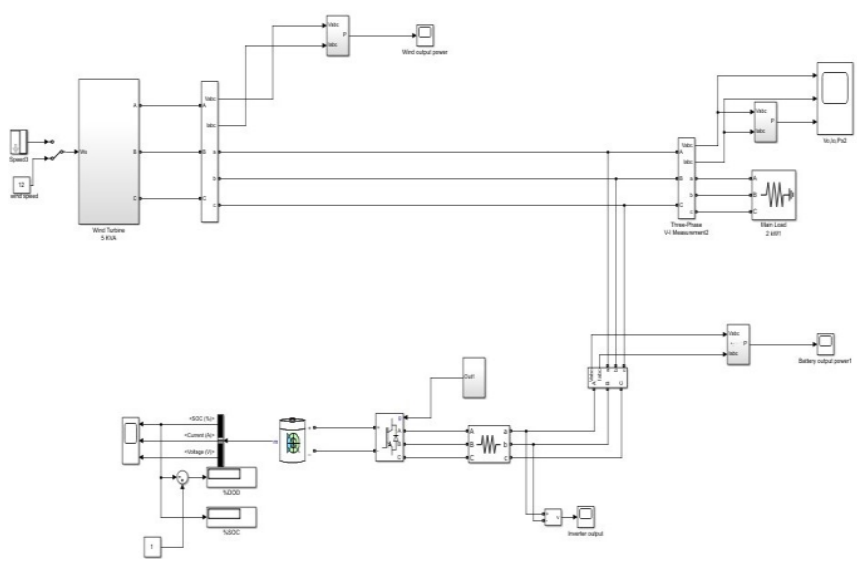

Fig. 3. Simulation Diagram of Battery Energy System supplying the critical load

In MATLAB simulation, for Diesel generator supplying the critical load, a three phase voltage and current measurement is added to measure the power at the input and also at the load side. Nominal input voltage used for per unit measurement(Vr.m.s $\phi-\phi)$ is equal to 280 and the output is measured considering only real power $(\mathrm{P})$ where the load is three-phase RLC load, the nominal phase to phase voltage (Vr.m.s)=200. An input of Diesel generator of 5KVA is converted into $4 \mathrm{KW}$ having $\mathrm{PF}$ as 0.8 produces the same $4 \mathrm{KW}$ power in the load side.

In Simulation of Battery Energy system to get the power output as $4 \mathrm{KW}$, the wind turbine is designed in a way to have 835* 103 joules/sec as nominal mechanical power output with wind speed $12 \mathrm{~m} / \mathrm{sec}$.

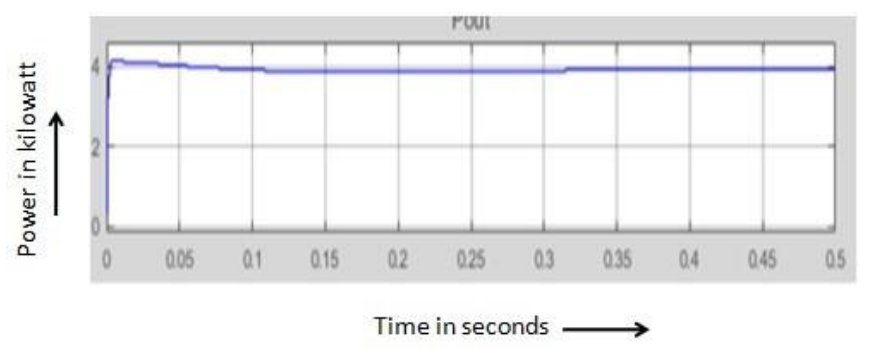

Fig. 4a: Output power of Diesel Generator

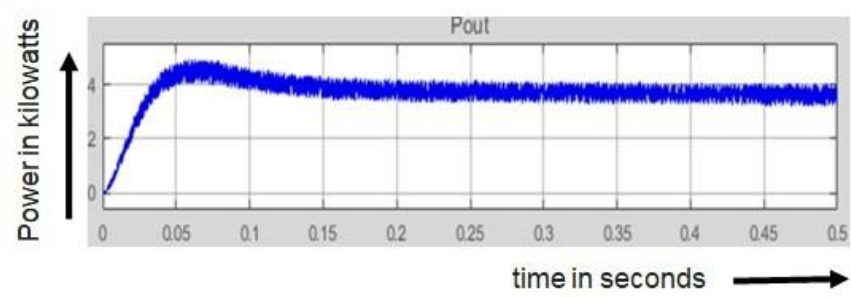

Fig. 4b: output power of battery

Fig. 4a and Fig. 4b depicts the power output from diesel generator and battery storage system and the results indicate both produce same power to supply a critical load of $4 \mathrm{KW}$. If a microcontroller is designed perfectly, then frequent shifting of power from diesel generator and battery is possible to minimize the usage of diesel to supply a critical load. 


\section{HARDWARE PROTOTYPE AND RESUlts OF THE PROPOSED SYSTEM}

The hardware prototype is tested before fabricating using proteus 7 design suit to verify its operation. It comprises of Arduino Uno, Battery, DC-DC converter, AC supply as diesel generator, DC to AC inverter, Step up transformer Single Chanel Relay, Voltage divider and charge controller, LCD, CFL lamp, voltage sensor, voltage regulator, LED The simulation diagram of the proposed hardware prototype is shown in Fig. 5

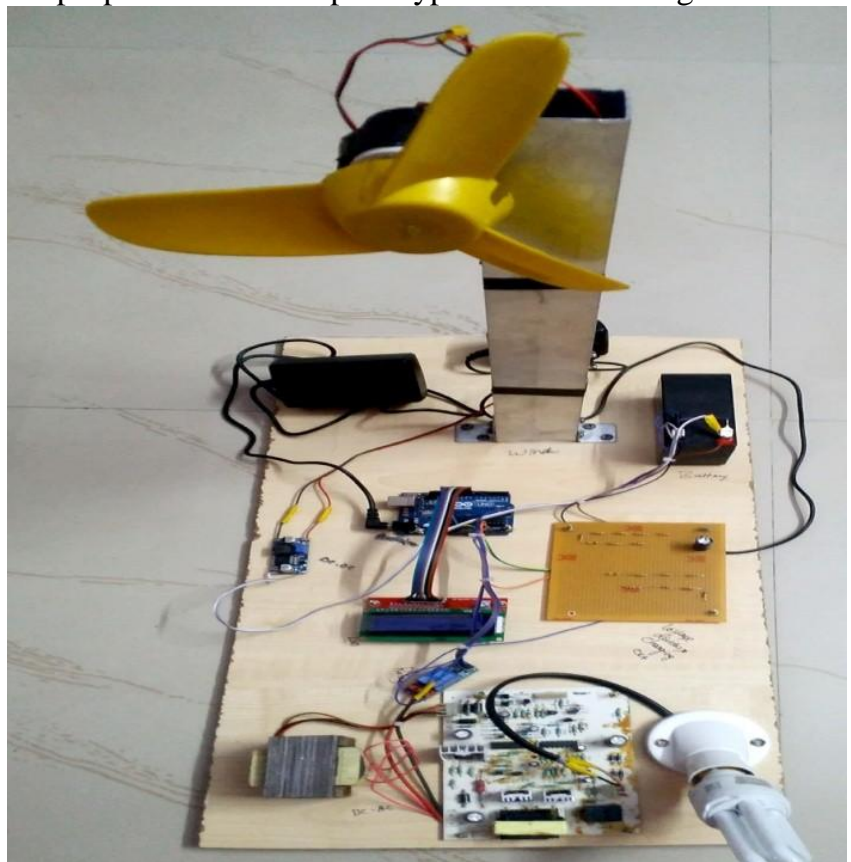

Fig. 5. Simulation Diagram of proposed System in proteus

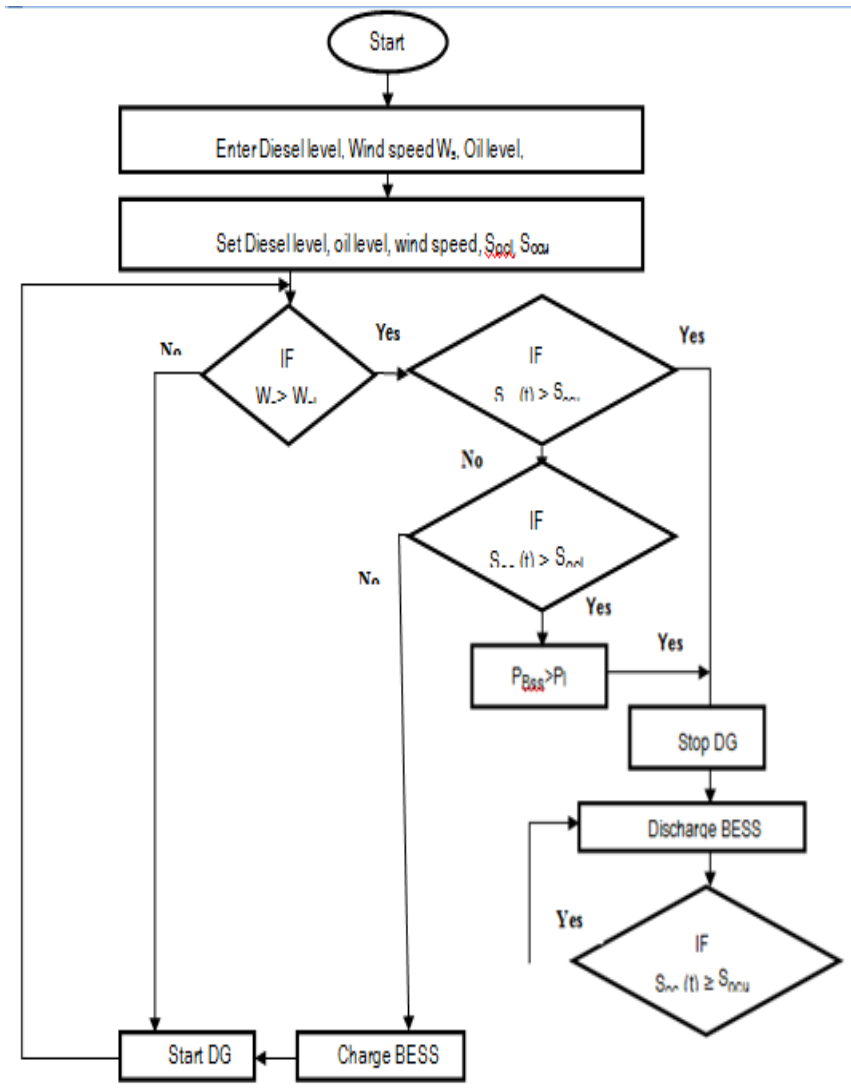

Fig.6. Flow Diagram of proposed Scheduling

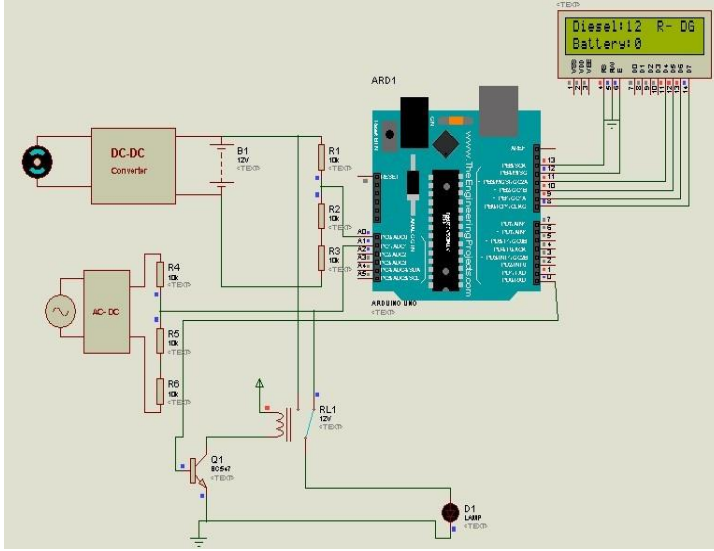

The intelligence of scheduling between Diesel generator and battery storage system lies in programming of a microcontroller and the flowchart depicting the flow of scheduling is shown in Fig. 6 and the program is embedded in Aurdino. After checking with simulation results, the same hardware prototype is fabricated as shown in Fig. 7 and tested for a critical load by changing the levels of the battery. If the level of the battery is up to its SOC limit battery is supplying its supply and when the battery level is below its SOC limit, AC supply as Diesel generator is supplying the load without any interruption.

Wind Turbine module is connected to battery through voltage divider and battery charger. The power levels of the battery are being checked and inputs are sent to microcontroller. If the power levels of battery are above SOC limit then the signal is sent to a relay so DC voltage is converted into Ac using DC to AC converter and it is being stepped up using step up transformer to a CLF bulb that acts as a load. A 230v AC supply is used instead of Diesel generator.

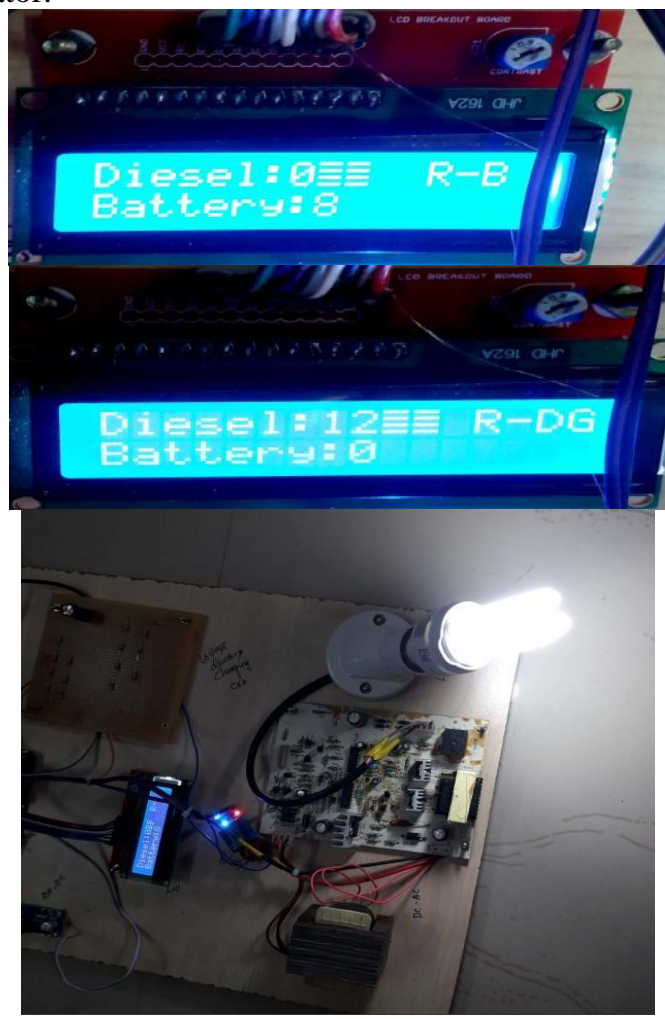

Fig. 8 Output of Proposed Hardware Prototype

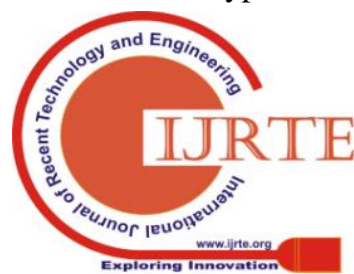


The results of hardware prototype are shown in Fig 8. The hardware is switched on with $230 \mathrm{~V}$ AC mains acting like a Diesel generator. The wind turbine is made to operate and once the battery has $80 \%$ of its rated value, microcontroller switches on the relay connected to the battery and switches off the relay connected to the AC source. Once the battery reaches $20 \%$ of its rated value, the reverse action takes place. The CFL bulb is glowing without any disturbance in the supply. The results proved microcontroller is sending signals to diesel and battery at proper time so that the critical load is served all the year around without disturbances.

\section{Conclusion}

In this paper, proper scheduling among Diesel generator and Battery Energy storage system to feed a critical load is done depending upon the SOC limits of the battery to minimize the Diesel usage. The scheduling program is verified using proteus simulation and hardware prototype experimental results proves the simulation results. In future, several isolated micro grids can be integrated using the centralized controller for an uninterrupted power supply.

\section{REFERENCES}

[1] Hwang, W.-H., Kim, S.-K., Lee, J.-H., 'Autonomous micro-grid design for supplying electricity in carbon-free island', Journal of Electrical Engineering and Technology 9(3) 9, pp. 1112-1118, May 2014.

[2] Cong-Long, N., Hong-Hee, L., Tae-Won, C., "Cost-optimized battery capacity and short-term power dispatch control for wind farm", IEEE Transactions on Industry Applications, Vol. 51,No.1, pp. 595-606, Jan - Feb 2015.

[3] Dan Wu, Fen Tang, Tomislav Dragicevic, Juan C. Vasquez, Josep M. Guerrero, "A Control Architecture to Coordinate Renewable Energy Sources and Energy Storage Systems in Islanded Microgrids" IEEE Transactions on Smart Grid., Vol.6, No.3, pp. 1156-1166, May 2015.

[4] Jose G. de Matos , Felipe S. F. e Silva , Luiz A. de S. Ribeiro, "Power Control in AC Isolated Microgrids With Renewable Energy Sources and Energy Storage Systems", IEEE transactions on Industrial Electronics, Vol. 62, No.6, pp. 3490-3498, June 2015.

[5] Md Abu Abdullah, Muttaqi K. M., Danny Sutanto, Agalgaonkar A. P. "An effective power dispatch control strategy to improve generation schedulability and supply reliability of a wind farm using a battery energy storage system', IEEE Transactions on Sustainable Energy, Vol.6, No.3, pp.1093-1102, July 2015

[6] Kanzumba Kusakana, "Optimal scheduled power flow for distributed photovoltaic/wind/diesel generators with battery storage system', IET Renewable Power Generation, Vol.9, No.8, pp. 916-924, Nov 2015.

[7] Yun-Su Kim ; Eung-Sang Kim ; Seung-Il Moon, “ Frequency and voltage control strategy of standalone microgrids with high penetration of intermittent renewable generation systems', IEEE Transactions on Power Systems, Vol.31,No.1, pp. 718-728, Jan 2016.

[8] Kwang Woo Joung, Dongmin Kim, DongHee Choi, Jung- Wook Park, Hee-Jin Lee, Seung-Mook Baek, Soo Hyoung Lee,Hak Ju Lee, Jun Bo Sim, "Energy management system for stable operation of isolated microgrid" CIRED, Open Access Proc. J., Vol. 2017, No. 1, pp. 1737-1740, Oct 2017.

[9] Moon H-J, Chang JW, Kim E-S, Moon SI. "Frequency-based wireless control of distributed generators in an isolated microgrid: A case of Geocha Island in South Korea." IEEE 52nd International Universities Power Engineering Conference (UPEC) 2017.

[10] Hyeon-Jin Moon, Jae Won Chang, Seok-Young Lee, Seung-Il Moon, "Autonomous active power management in isolated microgrid based on proportional and droop control” Energy Procedia, Vol. 153, Pages 48-55, October 2018.

\section{AUTHORS PROFILE}

R. Vanitha - Professor, Department of Electrical and Electronics Engineering, Sathyabama Institute of Science and Technology, Chennai, Tamilnadu, India.vanithasi@yahoo.com 